УДК 37.091.12:005.336.5:796]:004

DOI: https://doi.org/10.33989/2524-2474.2019.74.196652

ОКСАНА КОРНОСЕНКО

ORCID: 0000-0002-9376-176X

(Полтава)

Place of work: Poltava V.G. Korolenko National Pedagogical University

Country: Ukraine

Email: kornosenko@ukr.net

ВАЛЕНТИНА БОНДАРЕНКО

ORCID: 0000-0002-0326-0356

(Полтава)

Place of work: Poltava V.G. Korolenko National Pedagogical University

Country: Ukraine

Email:val.vl.bond@gmail.com

\title{
МАРІЯ БОНДАРЕНКО
}

ORCID: 0000-0002-4054-3937

(Полтава)

Place of work: Poltava V.G. Korolenko National Pedagogical University

Country: Ukraine

Email: utomme@gmail.com

\section{АНАЛІТИЧНІ АСПЕКТИ ВИКОРИСТАННЯ ІНФОРМАЦЙНО-КОМУНІКАЦІЙНИХ ТЕХНО- ЛОГІЙ У ПРОФЕСІЙНІЙ ДІЯЛЬНОСТІ ВЧИТЕЛЯ ФІЗИЧНОЇ КУЛЬТУРИ}

Розроблено класифікацію засобів інформаційно-комунікаційних технологій, в основі якої пріоритетні завдання (освітні, оздоровчі та виховні), які вирішує вчитель фізичної культури. Обумовлені групи поділено на типи (із використанням комп'ютера і без використання комп'ютера) та категорії (за допомогою Інтернету та без Інтернету). Групу реалізації освітніх завдань наповнено такими засобами ІКТ як: електронні енциклопедії, відеоматеріали, хмарні технології, телеконференція, ігри, інтерактивна дошка, прикладне програмне забезпечення, презентація, смартфон; оздоровчих - смартфон та фітнес-гаджети; виховних - електронні енциклопедії, відеоматеріали, ігри, інтерактивна дошка, презентація. Виявлено, що інформаційно-комунікаційні технології, як частина інноваційної освіти, сприяють ефективному навчанню, розвитку та вихованню, підвищенню зацікавленості й мотивації учнів до занять, їх застосування $є$ невід’ємною частиною професійної діяльності вчителя фізичної культури. вima.

Ключові слова: інформаційно-комунікаційні технології; вчитель фізичної культури; ос-

Постановка проблеми. Упровадження інформаційно-комунікаційних технологій (IKT) в систему національної освіти є одним із пріоритетних напрямів розвитку держави, про що засвідчено у законах України, зокрема «Про Концепцію Національної програми інформатизації» (Про Концепцію Національної програми, 2013), «Про Національну програму інформатизації» (Про Національну програму інформатизаuіiі, 2016). Основою для визначення державної політики у цьому напрямі став Закон України «Про Основні засади розвитку інформаційного суспільства в Україні на 2007-2015 роки» (Про Основні засади розвитку, 2007) у якому зазначено, що його упровадження забезпечить позитивні зміни у життєдіяльності суспільства, сприятиме якості та доступності послуг освіти.

На сучасному етапі закономірно постає питання перед учителем фізичної культури, як створити умови для забезпечення поступового переходу освіти на новий, якісний рівень. Реалізувати ідеї розвивального та особистісного навчання є можливість, у тому числі, і через упровадження інформаційно-комунікаційних технологій у навчально-виховний процес. Звернення до електронних ресурсів у процесі фізичного удосконалення мотивуватиме до свідомого й активного включення у рухову діяльність, отримання додаткової інформації щодо засобів, методів та форм покращення фізичних і рухових кондицій, зробить заняття цікавими та ефективними, навчить учнів працювати творчо та підвищить рівень самоконтролю.

Аналіз останніх досліджень і публікацій. Зважаючи на значний інтерес до проблеми застосування інформаційно-комунікаційних технологій у різних аспектах її досліджувало багато науковців. Так, у своїх дослідженнях Н. Вишневська, Л. Данильчук, О. Воронкіна, О. Замошнікова, І. Захарова, Г. Швачич визначили сутність поняття «інформаційно-комунікаційні технології» (Вишневська, 2014; Замошникова, 2008; Захарова, 2003; Швачич та ін., 2017); В. Данилюк, Д. Рождественська, В. Трайнєв, Г. Шиліна досліджували проблеми застосування інформаційних технологій у гуманітарних науках (Трайнев В., \& Трайнев, И., 2008); Н. Кононенко, З. Савченко, О. Харченко - у природничих науках (Кононенко, 2009); М. Жалдак, В. Мельніченко, Н. Морзе, В. Сумський - на уроках фізико-математичного циклу (Морзе, 2004); Т. Крамаренко, В. Назаренко, Ю. Юрчук - у підготовці фахівців у вищих закладах освіти (Назаренко, 2016); О. Аксьонова, А. Дубінчук, О. Кузнєцов, К. Сергієнко - на уроці фізичної культури (Дубінчук, 2001). Проте, сучасний стан використання інформаційно-комунікаційних технологій у професійній діяльності вчителя фізичної культури розкрито не достатньо. 
Мета дослідження - розробити класифікацію засобів інформаційно-комунікаційних технологій, які використовуються у процесі фізичного виховання; виявити особливості їх застосування у професійній діяльності вчителя фізичної культури.

На сучасному етапі успішне здійснення перетворень у суспільстві неможливе без удосконалення системи освіти, яка у багатьох напрямах не відповідає новим умовам життя. Сучасну молодь не задовольняють традиційні підходи до організації навчання, де все ще переважають репродуктивні методи і результатом цього невдоволення $€$ невміння і небажання дітей вчитися, не зацікавленість у власному розвитку та освіті.

Саме ця проблема вимагає створення нової системи освіти, характерною ознакою якої є здатність оперативно і гнучко реагувати на локальні й державні потреби; відтворювати в змісті освіти рівень розвитку техніки, технологій, менеджменту, бути відкритою для участі в розвитку освіти всіх громадян і суспільних організацій (Вишневська, 2014, с. 8-9).

У цьому аспекті на перше місце дедалі більше виходять нові інноваційні технології, як противага традиційному навчанню, яке, на думку дослідників, не забезпечує формування пізнавальної активності особистості (Дубінчук, 2001). У доповіді Римському клубові (1978) інноваційне навчання трактувалось як процес і результат освітньої діяльності. Таке навчання спонукає до ініціативності, творчого підходу до здобуття, а не отримання знань, розвитку різноманітних форм мислення і зорієнтоване на динамічні зміни в навколишньому світі (Олійник, 2004, с. 16).

Педагогічна інноватика, на думку В. Загв'язинського (Загвязинский, 1998, с. 23), дозволяє досить ефективно вирішувати завдання освіти і полягає у пошуку і впровадженні ідей, підходів, методів та технології, що раніше не використовувалися, та їх комплекс.

У сфері фізичної культури також існує досвід упровадження сучасних інноваційних технологій спрямованих на навчання учнівської молоді. Серед основних інноваційних технологій виділимо: спортивно орієнтоване фізичне виховання; особистісно орієнтоване фізичне виховання; олімпійська освіта; професійно орієнтоване фізичне виховання; моніторинг фізичного здоров'я і розвитку, фізичної підготовленості дітей, підлітків та молоді; нетрадиційні методи оздоровчої фізичної культури тощо (Дубінчук, 2001; Назаренко, 2016). Реалізація вказаних технологій може відбуватися на основі підходів: суто педагогічному (педагогічні технології), медико-біологічному (медико-біологічні технології); інформаційному (інформаційно-комунікаційні технології).

Ключовими, для дослідження, є інформаційно-комунікаційні технології тому, в першу чергу, варто визначити смислове значення їх складових - інформація, технологія та комунікація.

Вперше термін «інформаційно-комунікаційні технології» (ІКТ, від англ. Information and communications technology, ICT) вжито у 1997 році в доповіді Денніса Стівенсона для уряду Великобританії (Трайнев В., \& Трайнев И., 2008). Нині інформаційно-комунікаційні технології це поширений термін, який часто вживають у неоднозначному трактуванні «інформаційні технології», «нові інформаційні технології», «комп'ютерні технології».

Так І. Захарова визначає інформаційно-комунікаційні технології як конкретний спосіб роботи з інформаційними ресурсами у ході іхзбирання, обробки тапередавання (Захарова, 2003,с. 22).АН.Морзе розглядає ІКТ, якспосіб отримання інформації із використанням персональних комп'ютерів, комп'ютерних мереж і засобів зв'язку (Морзе, 2004, с. 12).

У Законі України «Про інформацію» (Про інформацію, 2012) це поняття ототожнюється з відомостями та/або даними та вказуються способи ії зберігання (матеріальні або електронні носії). В онлайн-енциклопедії Вікіпедія зміст поняття «інформація» визначається як нові, корисні для користувача відомості. Отже, у більшості досліджених джерел у сутність поняття «інформація» закладено нові відомості чи знання.

Аналіз науково-методичної літератури, зокрема соціологічного енциклопедичного словника дав підстави для розуміння поняття «комунікація» як процесу передавання й обміну інформацією, акту спілкування (Осипов, 1998, с. 133). За визначенням Ф. Шаркова «комунікація» - це засіб зв’язку певних об'єктів матеріального та духовного світу, спілкування, у процесі якого люди обмінюються інформацією, передача та масовий обмін інформацією тощо (Шарков, 2002, с. 178).У «Словнику паронімів української мови» термін «комунікаційний» автори розглядають у контексті відношення до шляхів сполучення, транспорту, ліній зв'язку, а також і як спілкування та обмін інформацією (Гринчишин, \& Сербенська, 2008, с. 141). Отже термін «комунікація» найчастіше використовують та пов'язують з наданням інформації, інформатизацією.

До певного часу, більшість дослідників розглядали термін «технологія» як процес пов'язаний з виробництвом, медициною, політикою, економікою. Так, при визначенні поняття «технологія» учена Н. Морзе розглядала іï як сукупність методів, засобів досягнення високої ефективності у певному виді діяльності (Морзе, 2004, с. 10). У тлумачному словнику сучасної української мови це поняття співвідноситься не лише з виробничими операціями чи послугами, а водночас $є$ і способом обробки чи переробки інформації (Бусел, 2009 , с. 1448). Нині учені, вживають його стосовно освіти, зокрема навчання, й сутність сучасної технології вбачають у досягненні суб'єктом поставлених цілей, використовуючи раціональний спосіб.

Аналіз обумовленихпонять дозволяєузагальнити й розглядати поняття «інформаційно-комунікаційні технології в освіті» як сукупність програмних засобів, методів і способів, які забезпечують ефективне засвоєння матеріалу у результаті передачі, обробки, одержанні, обміну, зберігання нових відомостей за допомогою сучасних технічних ресурсів.

Ретроспективний аналіз еволюції застосування терміну «технологія» стосовно інформатизації, допоміг встановити, що вони розвивалися як інструмент поширення інформації і пройшли шлях від використання елементарного приладдя передавання письмової інформації до мультифункціонального (синергетичного) призначення з використанням мережі Інтернет. Наведемо дані аналізу у таблиці 1. 
Періодизація поширення інформації за видами інструментарію

Таблиця 1.

\begin{tabular}{|c|c|c|c|}
\hline Періодизація поширення & Назва етапу & Інструмент & Мета \\
\hline $\begin{array}{c}\text { 1-й етап } \\
\text { (до другої половини XIX ст.) }\end{array}$ & 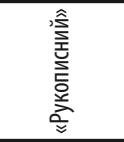 & Перо, чорнильниця, книга & Подання інформації в доступній формі \\
\hline $\begin{array}{c}\text { 2-й етап } \\
\text { ( кінець XIX ст.) }\end{array}$ & 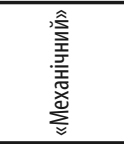 & Друкарська машинка, телефон, диктофон & Подання інформації в більш зручними засобами \\
\hline $\begin{array}{c}\text { 3-й етап } \\
(40-60-\text {-і рр. XX ст.) }\end{array}$ & 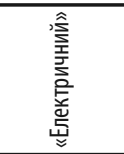 & $\begin{array}{c}\text { Великі ЕОМ і відповідне програмне забезпечення, } \\
\text { електричні друкарські машинки, ксерокси, порта- } \\
\text { тивні диктофони }\end{array}$ & Формування змісту інформації \\
\hline $\begin{array}{c}\text { 4-й етап } \\
\text { (початок 70-х рр. XX ст.) }\end{array}$ & 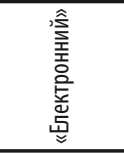 & $\begin{array}{c}\text { Великі ЕОМ і створені на їхній базі автоматизовані } \\
\text { системи управління (АСУ) й інформаційно-пошукові } \\
\text { системи, оснащені широким спектром базових і спе- } \\
\text { ціалізованих програмних комплексів }\end{array}$ & $\begin{array}{c}\text { Формування змістовної сторони інформації для управлін- } \\
\text { ського середовища різних сфер суспільного життя, особливо } \\
\text { на організацію аналітичної роботи }\end{array}$ \\
\hline $\begin{array}{c}\text { 5-й етап } \\
\text { (середина 80-х рр. XX ст.) }\end{array}$ & 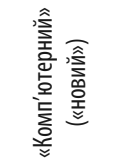 & $\begin{array}{l}\text { Персональний комп'ютер із широким спектром стан- } \\
\text { дартних програмних продуктів різного призначення }\end{array}$ & $\begin{array}{c}\text { Створення систем підтримки прийняття рішень певними спе- } \\
\text { ціалістами }\end{array}$ \\
\hline 6-й етап (тільки встановлюється) & 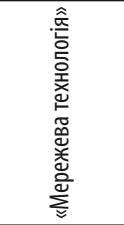 & Галузі глобальні і локальні комп'ютерної мережі & Використання глобальної комп'ютерної мережі Internet \\
\hline
\end{tabular}

Для комплексного розуміння інформаційно-комунікаційних технологій їх варто систематизувати. Нині, ще не сформовані єдині підходи до класифікації технологій, однак існують окремі групування за певними ознаками, які залежать від функцій.

Зокрема, О. Замошнікова класифікує технологіїзалежно від функцій в організації освітнього процесу іподіляє їх на:

- інформаційно-навчальні (електронні бібліотеки, електронні книги, словники, навчальні довідники, комп'ютерні програми тощо);

- інтерактивні (електронна пошта, електронні конференції);

- пошукові (реалізуються через каталоги, пошукові системи) (Замошникова, 2008, с. 78-83).

Н. Кононенко виокремлює кілька найважливіших видів інформаційно-комунікаційних технологій: мультимедіа, інтернет, телебачення, відеозаписи, поміж яких виокремлює мультимедіа, як найефективніший засіб комплексного подання інформації через текст, звук, відео, дво- та тривимірну графіку (Корносенко, 2009, с. 38).

А. Зубов розглядає інформаційно-комунікаційні технології комплексно та вказує на їх освітні компоненти:

1. Теоретичні засади (поняття і закони інформатики).

2. Методи вирішення завдань (моделювання, системний аналіз, системне проектування, методи передачі, збору, продукування, накопичення, збереження, обробки, передачі та захисту інформації).

3. Засоби вирішення завдань:

- апаратні (персональний комп'ютер і його основні складові, локальні та глобальні мережі, сучасне периферійне обладнання);

- програмні (системні, прикладні, інструментальні) (Швачич та ін., 2017, с. 9).

Таким чином, інформаційно-комунікаційні технології в освіті є важливим інструментом передачі інформації для формування знань. Диференціація терміну «інформаційно-комунікаційні технології» на складові дозволила з'ясувати, що в смисловому значенні поняття «інформація» сприймається як нові відомості чи знання; «комунікація», як засіб зв'язку, передачі та масового обміну інформацією, а «технологія», як процес ії̈ передавання.

Перехід української освіти на європейські стандарти, обумовлює важливість педагогічної праці вчителя фізичної культури як компетентного, творчого й активного фахівця, здатного з урахуванням сучасних вимог ринку праці на високому рівні розробляти та застосовувати освітні технології, у тому числі й інформаційнокомунікаційні, які значно підвищать мотивацію та інтерес школярів до занять фізичною культурою.

Педагогічна діяльність учителя фізичної культури спрямована на вирішення освітніх, оздоровчих і виховних завдань у системі урочних і позаурочних занять та формування в учнів стійкої мотивації до збереження свого здоров'я, підвищення рівня рухової активності, гармонійного розвитку природних (фізичних) здібностей за допомогою засобів фізичного виховання. Використання ІКТ у практиці фізичної культури до- 
нині досліджено доволі фрагментарно, відповідно, пропонуємо ці технології систематизувати за такими напрямами: навчальний процес, спортивне тренування і змагання у позакласній та позашкільній роботі, оздоровча фізична культура для самовдосконалення.

Аналіз сучасних науково-педагогічних джерел з питання використання інноваційних засобів інформування в освітньому процесі дозволив нам узагальнити засоби інформаційно-комунікаційних технологій та виокремити 3-поміж них комп'ютерні та некомп'ютерні шляхи поширення інформації з використанням та без використання можливостей мережі Інтернет. Класифікуємо засоби ІКТ відповідно до груп завдань, які учитель вирішує у процесі фізичного виховання та представимо на рисунку 1.

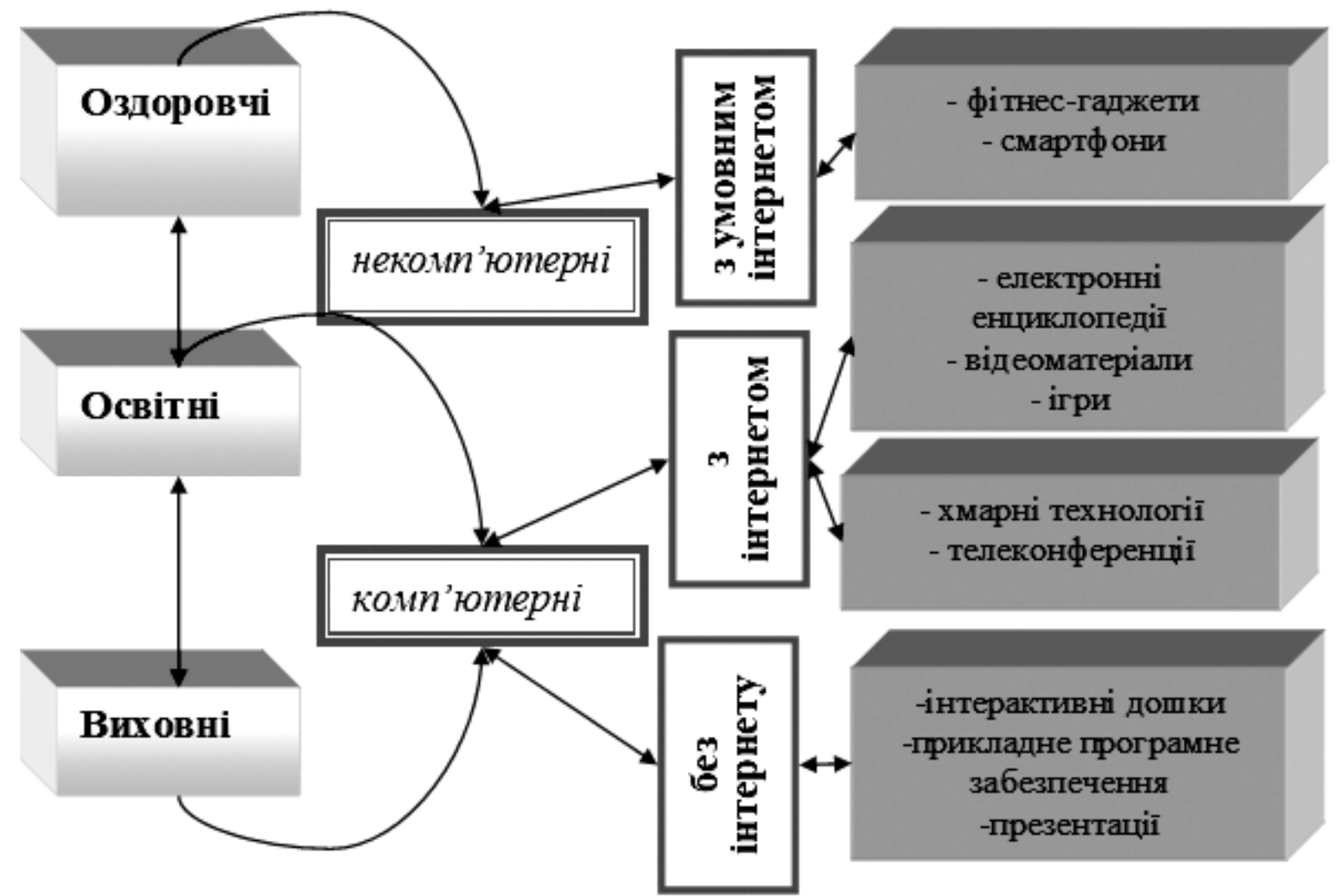

Рис.1. Засоби інформаційно-комунікаційних технологій, які використовуються у процесі фізичного виховання

Зміст освітніх завдань передбачає навчання техніці фізичних вправ та застосування набутих знань, умінь і навичок у повсякденному житті у процесі самовдосконалення. У різних формах рухової активності якість вирішення освітніх завдань можна підвищувати використовуючи комп'ютерні технології з доступом до Інтернету (електронні енциклопедії, відеоматеріали, хмарні технології, телеконференції, ігри) і без доступу (інтерактивна дошка, прикладне програмне забезпечення у вигляді діаграм, схем, таблиць та презентації), так і не комп’ютерні з умовною функцією використання Інтернету (смартфон).

Оздоровчі завдання реалізуються у процесі забезпечення оптимального розвитку фізичних якостей i, на їх основі, вдосконалення фізичного розвитку, загартування організму, формування правильної постави, корекція фігури, зміцнення і збереження здоров'я. Для організації контролю і самоконтролю фізичного стану та здоров'я, отримання методичних рекомендацій з оздоровчої фізичної культури активно використовують смартфони та фітнес-гаджети. Вони умовно можуть використовуватися без Інтернету, але залежать від додатку, який завантажується із використанням мережі Інтернет.

Виховання інтересу до фізичної культури, забезпечення позитивного впливу заняття фізичними вправами на розвиток моральних і вольових якостей, єдність фізичного і духовного розвитку особистості учня наповнюють зміст виховних завдань. Такі комп'ютерні засоби ІКТ з використанням Інтернету, як електронні енциклопедії, відеоматеріали, ігри та ті, які не потребують допомоги Інтернету, а саме - інтерактивна дошка, презентації матимуть практичну доцільність при вирішенні виховних завдань.

Висновки. У ході аналізу науково-методичної літератури з'ясовано, що проблеми теоретичного обгрунтування, розробки й упровадження сучасних інформаційно-комунікаційних технологій у процес викладання предметів математичного, природничого чи гуманітарного циклів вивчено у багатьох працях. Дослідження способів використання ІКТ здійснюються і в галузі фізичної культури, але вектор пошуків спрямовано на застосування мультимедійного навчання, а інші засоби й підходи технічних інновацій, що протиставляються традиційній освіті, розглянуто фрагментарно. 
Застосування методу аналізу джерел сучасної науково-методичної літератури, дозволив розробити класифікацію засобів інформаційно-комунікаційних технологій, в онові яких пріоритетні завдання (освітні, оздоровчі та виховні), які вирішує вчитель фізичної культури. До освітніх належать: електронні енциклопедії, відеоматеріали, хмарні технології, телеконференція, ігри, інтерактивна дошка, прикладне програмне забезпечення, презентація, смартфон; до оздоровчих - смартфон та фітнес-гаджети; до виховних - електронні енциклопедії, відеоматеріали, ігри, інтерактивна дошка, презентація. Обумовлені групи поділено на типи (із використанням комп'ютера і без використання комп’ютера) та категорії (за допомогою Інтернету та без Інтернету). Інформаційно-комунікаційні технології, як частина інноваційної освіти, сприяють ефективному навчанню, розвитку та вихованню, підвищенню зацікавленості й мотивації учнів до занять, їх застосування $€$ частиною професійної діяльності вчителя фізичної культури.

\section{СПИСОК ВИКОРИСТАНОЇ ЛІТЕРАТУРИ}

Великий тлумачний словник сучасної української мови / уклад. В Т. Бусел. Ірпінь : Перун, 2009. 1736 с.

Вишневська Н. Головні тенденції реформування шкільної освіти в країнах світу в 80-90-х роках XX століття. Нова педагогічна думка. 2014. № 1. C. 10-15. URL: http://nbuv.gov.ua/UJRN/Npd_2014_1_4).

Дубінчук А. Фізична культура: впроваджуємо сучасні технології. Фізичне виховання в школі. 2001 № 24. С. 13-17.

Загвязинский В. И. Педагогическое творчество учителя. Москва : Педагогика, 1987. 160 с.

Замошникова О. В. Новые информационные технологии в образовании. Новые информационные технологии в образовании : материалы междунар. науч.-практ. конф. (Екатеринбург, 26-28 февраля 2008 г.). Екатеринбург : Изд-во Рос. гос. проф.-пед. ун-т., 2008. Ч. 2. С. 78-83.

Захарова И. Г. Информационные технологии в образовании. Москва : Академия, 2003. 192 с.

Кононенко Н. Мультимедіа на уроках хімії. Біологія і хімія в школі. 2009. № 4. С. 38-39.

Морзе Н. В. Методика навчання інформатики : у 3 ч. Київ : Навч. книга, 2004. Ч. 1: Загальна методика навчання інформатики. 256 с.

Назаренко В. Переваги і перспективи використання хмарних технологій у навчально-виховному процесі. Нова педагогічна думка. 2016. № 4. C. 97-99. URL: http://nbuv.gov.ua/UJRN/Npd_2016_4_25.

Олійник О. Про трактування поняття “педагогічна технологія”. Рідна школа. 2004. № 2. С. 16-19.

Про інформацію : Закон України № 2658-XII від 10.08.2012. URL: https://zakon.rada.gov.ua/laws/show/265712/ed20120810/find/sp:max15?text=\%B2\%ED\%F4\%EE\%F0\%EC\%E0\%F6\%B3\%FF

Про Концепцію Національної програми інформатизації : Закон України № 75/98-BP 11.08.2013. URL: https://zakon.rada.gov.ua /laws/main/75/98-вр

Про Національну програму інформатизації: Закон України № 74/98-BP 01.08.2016. URL: https://zakon.rada.gov.ua /laws/main/74/98-вр

Про Основні засади розвитку інформаційного суспільства в Україні на 2007-2015 роки : Закон України № 537-V від 09.01.2007 p. URL: https://zakon.rada.gov.ua/laws/show/537-16

Словник паронімів української мови / уклад.: Д. Г. Гринчишин, О. А. Сербенська. Київ : Освіта, 2008. 320 с.

Социологический энциклопедический словарь / ред.. Г. В. Осипов. Москва : ИНФРА-М-НОРМА, 1998. 488 с.

Сучасні інформаційно-комунікаційні технології / Г. Г. Швачич та ін. Дніпро : НМетАУ, 2017. 230 с.

Трайнев В. А., Трайнев И. В. Информационные коммуникационные педагогические технологии (обобщения и рекомендации). Москва : Дашков и К, 2008. 280 с.

Шарков Ф. И. Основы теории коммуникации. Москва, 2002. 246 с.

\section{REFERENCES}

Busel, V. T. (Comp.). (2009). Velykyi tlumachnyi slovnyk suchasnoi ukrainskoi movy [Great Dictionary of Modern Ukrainian]./ Irpin: Perun [in Ukrainian].

Dybinchyk, A. (2001). Fizychna kyltypa: vppovadzhuiemo suchasni texnolohiі [Фізична культура: впроваджуємо сучасні технологіï]. Fizychne vyхovannia v shkoli [Physical education at school], 24, 13-17 [in Ukrainian].

Hrynchyshyn, D. H., \& Serbenska, O. A. (Comps.). (2008). Slovnyk paronimiv ukrainskoi movy [Dictionary of paronyms of the Ukrainian]. Kyiv: Osvita [in Ukrainian].

Kononenko, N. (2009). Multymedia na urokakh khimii [Multimedia in chemistry lessons]. Biolohiia i khimiia v shkoli [Biology and chemistry at school], 4, 38-39 [in Ukrainian].

Morze, N. V. (2004). Metodyka navchannia informatyky [Methods of teaching computer science] (Ch. 1: Zahalna metodyka navchannia informatyky [General methodology of teaching computer science]. Kyiv: Navch. knyha [in Ukrainian].

Nazarenko, V. (2016). Perevahy i perspektyvy vykorystannia khmarnykh tekhnolohii u navchalno-vykhovnomu protsesi [Advantages and prospects of using cloud technologies in the educational process]. New Pedagogical Thought, 4, 97-99. Retrieved from http://nbuv.gov.ua/UJRN/Npd_2016_4_25.

Oliinyk, O. (2004). Pro traktuvannia poniattia "pedahohichna tekhnolohiia" [On the interpretation of the concept of "pedagogical technology"]. Ridna shkola [Native school], 2, 16-19 [in Ukrainian].

Osipov, G. V. (Ed.). (1998). Sotsiologicheskii entsiklopedicheskii slovar' [Sociological Encyclopedic Dictionary]. Moskva: INFRA-MNORMA [in Russian].

Pro informatsiiu [About information]. № 2658-XII. Retrieved from https://zakon.rada.gov.ua/laws/show/265712/ed20120810/find/sp:max15?text=\%B2\%ED\%F4\%EE\%F0\%EC\%E0\%F6\%B3\%FF [in Ukrainian].

Pro Kontseptsiiu Natsionalnoi prohramy informatyzatsii [About the Concept of the National Informatics Program]. № 75/98-VR. Retrieved from https://zakon.rada.gov.ua/laws/main/75/98-vr [in Ukrainian].

Pro Natsionalnu prohramu informatyzatsii [About the National Informatics Program]. № 74/98-VR. Retrieved from https://zakon.rada.gov.ua/laws/main/74/98-vr [in Ukrainian].

Pro Osnovni zasady rozvytku informatsiinoho suspilstva $v$ Ukraini na 2007-2015 roky [About the Basic principles of development of information society in Ukraine for 2007-2015]. № 537-V. Retrieved from https://zakon.rada.gov.ua/laws/show/537-16 [in Ukrainian]. 
Sharkov, F. I. (2002). Osnovy teorii kommunikatsii [The basics of communication theory]. Moskva [in Russian].

Shvachych, H. H., Tolstoi, V. V., Petrechuk, L. M., Ivashchenko, Yu. S., Huliaieva, O. A., \& Sobolenko O. V. (2017). Suchasni informatsiino-komunikatsiini tekhnolohii [Modern information and communication technologies]. Dnipro: NMetAU [in Ukrainian].

Trainev, V. A., \& Trainev, I. V. (2008). Informatsionnye kommunikatsionnye pedagogicheskie tekhnologii (obobshcheniya i rekomendatsii) [Information and communication pedagogical technologies (generalizations and recommendations)]. Moskva: Dashkov i K [in Russian].

Vyshnevska, N. (2014). Holovni tendentsii reformuvannia shkilnoi osvity v krainakh svitu v 80-90-kh rokakh XX stolittia [The main tendencies of reforming school education in the countries of the 80-90s of the XX century]. New Pedagogical Thought, 1, 10-15. Retrieved from http://nbuv.gov.ua/UJRN/Npd_2014_1_4) [in Ukrainian].

Zagvyazinskii, V. I. (1987). Pedagogicheskoe tvorchestvo uchitelya [Pedagogical creativity of the teacher]. Moskva: Pedagogika [in Russian].

Zakharova, I. G. (2003). Informatsionnye tekhnologii v obrazovanii [Information Technology in Education]. Moskva: Akademiya [in Russian].

Zamoshnikova, O. V. (2008). Novye informatsionnye tekhnologii v obrazovanii [New Information Technologies in Education]. In Novye informatsionnye tekhnologii v obrazovanii [New information technologies in education]: Proceeding of the International Scientific Conference (Ch. 2, pp. 78-83). Ekaterinburg: Izd-vo Ros. gos. prof.-ped. un-t. [in Russian].

\author{
OKSANA KORNOSENKO \\ Place of work: Poltava V.G. Korolenko National Pedagogical University \\ Country: Ukraine \\ Email: kornosenko@ukr.net \\ VALENTINA BONDARENKO \\ Place of work: Poltava V.G. Korolenko National Pedagogical University \\ Country: Ukraine \\ Email:val.vl.bond@gmail.com \\ MARIA BONDARENKO \\ Place of work: Poltava V.G. Korolenko National Pedagogical University \\ Country: Ukraine \\ Email: utomme@gmail.com
}

ANALYTICAL ASPECTS OF USING THE INFORMATION AND COMMUNICATION TECHNOLOGIES IN PROFESSIONAL ACTIVITY OF PHYSICAL CULTURE TEACHER

In the article the content of the basic concepts of the research is analysed, such as «information», «communication», «information and communication technologies in education». The concept "information" is considered as new information or knowledge; «communication» is viewed as a mean of communication, transmission and mass exchange of information; «information and communication technologies in education» is observed as a set of software, methods and ways that ensure the effective mastering of material as a result of transfer, processing, receipt, exchange, storage of new information with the help of modern technical resources.

Classification of means of information and communication technologies is worked out, which focuses on priority tasks (educational, health improving and upbringing), that physical culture teacher solves. These specified groups are divided into types (with the use of computer and without using it) and categories (with the help of Internet and without it). Group of realization of educational tasks involves such means of ICT as: electronic encyclopaedias, video data, cloudy technologies, TV conference, games, interactive board, application software, presentation, smartphone; health improving - smartphone and fitness gadgets; upbringing - electronic encyclopaedias, video data, games, interactive board, presentation. It is discovered that information and communication technologies, as part of innovative education, assist the effectiveness of education, development and upbringing, increase of the personal interest and motivation of students to lessons, their application is inalienable part of professional activity of physical culture teacher.

It is discovered that in various forms of motor activity the quality of solving educational problems can be improved by using computer technologies with Internet access, without access (interactive whiteboard, application software in the forms of diagrams, charts, tables and presentations) and non-computer resources with notional use of the Internet (smartphones). It has been found out that to organize monitoring and self-monitoring for physical health, in order to get methodological recommendations about health-improving physical culture, it is appropriate to use smartphones and fitness gadgets that can function without the Internet, but depend on an application that is downloaded from the Internet.

It has been also found out that the efficiency of solving educational tasks in the process of physical education can be enhanced by computer tools while using the Internet (electronic encyclopaedias, video materials, games) and those that do not need the Internet (interactive whiteboards, presentations).

Keywords: information and communication technologies; physical culture teacher; education. 